Schweizerische Zeitschrift für

Swiss Journal of Integrative Medicine

Josef Roos

Wer hätte gedacht, dass der Openday der Aeskulap auf eine so grosse Resonanz stossen und über $1500 \mathrm{Be}$ sucherinnen und Besucher anlocken könnte? Dennoch waren die Mitarbeiterinnen und Mitarbeiter der Klinik bestens gerüstet, die grosse Gästeschar zu bewältigen und ihr das Haus, seine Philosophie und seine Therapien mit viel Engagement näherzubringen.

An den unzähligen Tischständen wurden Fragen beantwortet und informiert, Geräte gezeigt und vorgeführt, Workshops durchgeführt und zahlreiche Vorträge gehalten. Man konnte Yoga ausprobieren, malen oder
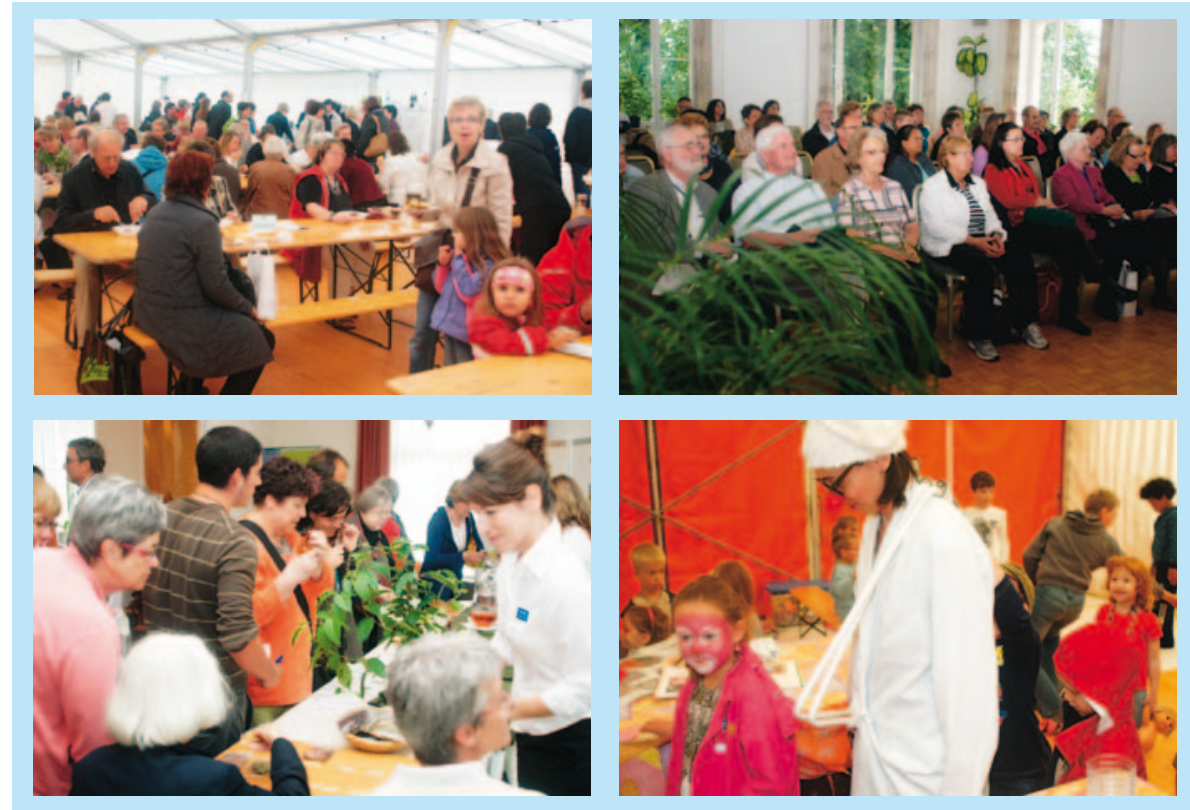

\section{Fortbildung}

Schweiz Z Ganzheitsmed 2010;22:290

DOI: 10.1159/000320102 mit einem Tag der offenen Tür Erwartungen wurden damit übertroffen. an einem Gleichgewichtswettbewerb teilnehmen. Sämtliche Bereiche der Aeskulap-Klinik gewährten damit den interessierten Besucherinnen und Besuchern einen einmaligen Einblick in ihr Aufgabenfeld und in die Welt der Ganzheitsmedizin. Vom Labor über die Infusionsabteilung bis zum Arztzimmer war alles offen und zugänglich. Die grosse Besucherschar war schliesslich ein deutliches Indiz, dass die Ganzheitsmedizin auf breites Interesse in der Bevölkerung stösst.

\section{Grossartige Speisen}

Auch für Familien war am grossen Openday gesorgt. In einem Zelt be-

\title{
Aeskulap-Klinik von \\ Publikumsaufmarsch überrascht
}

Die Aeskulap-Klinik feierte ihren 20. Geburtstag

Der Tag der offenen Tür anlässlich des 20-jährigen Bestehens der AeskulapKlinik am 19. Juni 2010 entwickelte sich zu einem Grosserfolg. Über 1500 Besucherinnen und Besucher fanden sich trotz strömendem Regen ein und machten den Grossanlass zu einem unvergesslichen Tag. Selbst die kühnsten

fand sich ein Kinderparadies, wo mehrere Betreuerinnen mit den Kleinen spielten. Eine Clownin sorgte dabei für Ausgelassenheit und Stimmung.

Selbstverständlich kam auch das leibliche Wohl nicht zu kurz. Im grossen Festzelt wurden die Besucher nach dem Rundgang reichlich und kostenlos mit Paella, Bratwürsten und Salaten verwöhnt. Auch die Nachspeisen liessen nichts zu wünschen übrig. Insgesamt war der Anlass ein grossartiger und gelungener Tag der offenen Tür mit einer mitreissenden Stimmung und Dynamik.

Eindrücke vom Openday der Aeskulap-Klinik.

\section{KARGER}

Fax +497614520714 Information@Karger.d www.karger.com
() 2010 S. Karger GmbH, Freiburg
Dr. Josef Roos (Medienverantwortlicher) Aeskulap-Klinik

Gersauerstrasse 8, 6440 Brunnen, Schweiz

Tel. +41 825-4747, Fax -4965

josef.roos@aeskulap.com 